\title{
Coincidence best proximity point theorems for proximal Berinde $g$-cyclic contractions in metric spaces
}

\author{
Chalongchai Klanarong ${ }^{1}$ and Inthira Chaiya ${ }^{1 *}$ (D)
}

"Correspondence:

inthira.c@msu.ac.th

'Department of Mathematics,

Faculty of Science, Mahasarakham

University, Mahasarakham 44150,

Thailand

\begin{abstract}
In this paper, we introduce the notions of proximal Berinde $g$-cyclic contractions of two non-self-mappings and proximal Berinde $g$-contractions, called proximal Berinde $g$-cyclic contraction of the first and second kind. Coincidence best proximity point theorems for these types of mappings in a metric space are presented. Some examples illustrating our main results are also given. Our main results extend and generalize many existing results in the literature.
\end{abstract}

MSC: $47 \mathrm{H} 10 ; 54 \mathrm{H} 25$

Keywords: Best proximity point; Cyclic contraction; Proximal Berinde g-cyclic contraction; Coincidence best proximity point

\section{Introduction}

Fixed point theory has an important role in the study of theory of nonlinear equations. Several problems can be formulated as equations of the form $J x=x$, where $J$ is a selfmapping in a metric space or in other spaces as appropriate framework. Fixed point theory concerning contraction and generalized contractions has been studied by many mathematicians. It is well-known that the first person who gave the idea of a contraction was Banach [4]. In 1922, he introduced the concept of a contraction of a self-mapping in a metric space and proved that every contraction mapping from a complete metric space $X$ into itself has a unique fixed point. Later, in 2004, the Romanian mathematician Berinde [7] introduced the concept of a weak contraction mapping in a metric space, which is the generalization of the contraction mapping. He proved that every weak contraction mapping from a complete metric space $X$ into itself has a fixed point. In addition to the references mentioned above, there are two interesting articles about the existence of a fixed point for a single-valued mapping which was studied by Hussain et al. [16] and Latif et al. [20]. Although fixed point theory has great importance in solving nonlinear equations of the form $J x=x$, where $J$ is a self-mapping, if $J$ is a non-self-mapping, then it is possible that $J$ has no fixed points. But we know that the distance between $x$ and $J x$ is always greater than or equal to zero. So $d(x, J x) \geq 0$ for all $x$ in the domain of $J$. Hence, it raises the following

(c) The Author(s) 2021. This article is licensed under a Creative Commons Attribution 4.0 International License, which permits use, sharing, adaptation, distribution and reproduction in any medium or format, as long as you give appropriate credit to the original author(s) and the source, provide a link to the Creative Commons licence, and indicate if changes were made. The images or other third party material in this article are included in the article's Creative Commons licence, unless indicated otherwise in a credit line to the material. If material is not included in the article's Creative Commons licence and your intended use is not permitted by statutory regulation or exceeds the permitted use, you will need to obtain permission directly from the copyright holder. To view a copy of this licence, visit http://creativecommons.org/licenses/by/4.0/. 
question: Can we find an element $x$ in the domain of $J$ such that

$$
d(x, J x)=\min _{y \in D(J)} d(y, J y)
$$

where $D(J)$ is the domain of $J$. From the above questions, this resulted in the study of a best proximity point theorem. Let $(X,\|\cdot\|)$ be a normed vector space and $C$ a nonempty compact convex subset in $X$. In 1969, Fan [12] was the first to study the best proximity point theorem, and he proved that if $J: C \rightarrow X$ is a contraction non-self-mapping, then there exists $x^{*} \in C$ such that $\left\|x^{*}-J x^{*}\right\|=d\left(J x^{*}, C\right)$, where $d\left(J x^{*}, C\right)=\min \left\{\left\|J x^{*}-x\right\|: x \in\right.$ $C$ \}. Clearly, if $J(C) \subseteq C$, then $x^{*}$ is a fixed point of $J$. Later, Kirk et al. [19] studied and introduced the concept of a cyclic mapping in the context of a metric space. Moreover, they proved that if $J: Y \cup Z \rightarrow Y \cup Z$ is a cyclic mapping on a complete metric space $(X, d)$ and $J$ satisfies the condition

$$
d(J x, J y) \leq \alpha d(x, y)
$$

for some $\alpha \in[0,1)$ and for all $x \in Y, y \in Z$, then $Y \cap Z \neq \emptyset$ and $J$ has a unique fixed point in $Y \cup Z$. Three years later, Eldred and Veeramani [11] introduced the concept of a cyclic contraction and proved the existence and convergence results of a best proximity point for the cyclic contraction in a uniformly metric space and a convex Banach space, which is an extension of the results of Kirk et al. [19] to the case $Y \cap Z \neq \emptyset$. Based on the concept of Eldred and Veeramani [11], many mathematicians got interested in studying best proximity point theorems in various directions. More details can be found in $[1,9,13,15,17,21,22]$.

In 2011, Gabeleh and Abker [15] studied and discussed the existence and convergence of a best proximity point of a semicyclic contraction pair $(J, T)$, where $J$ and $T$ are selfmappings on $Y \cup Z$. In the same year, Basha [5] introduced the concept of a proximal cyclic contraction of two mappings $J$ and $T$. Furthermore, the author gave the concept of a proximal contraction of the first and the second kind for non-self-mappings. Especially, the author obtained some interesting results on best proximity points for there mappings in a complete metric space.

In addition to the above article, many famous researchers have been interested in studying best proximity point theory in different directions. For more details, see Ayari et al. [3], Sehgal and Singh [25], Vetrivel et al. [26], Anuradha and Veeramani [2], Basha and Veeramani [6], Kirk et al. [18], Raj [23], Gabeleh [14], Abkar and Gabeleh [1], Du and Lakzian [10], Eldred and Veeramani [11], Reich [24], and the references therein.

The main aim of this paper is to study a coincidence best proximity point result for proximal Berinde $g$-cyclic contraction of two non-self-mappings, and a coincidence best proximity point result for proximal Berinde $g$-contraction of the first and second kind on a complete metric space.

\section{Preliminaries}

In this section, we will review the notations and definitions to provide basic knowledge for creating the main results of this article. 
Definition 2.1 ([7]) Let $(X, d)$ be a metric space. A mapping $J: X \rightarrow X$ is called a weak contraction if there exist $k \in(0,1)$ and $L \geq 0$ such that

$$
d(J x, J y) \leq a d(x, y)+L d(x, J y), \quad \text { for all } x, y \in X .
$$

Remark 2.2 In some articles, the mapping $J$ satisfying the condition (2.1) is called an almost contraction (see, [8]).

Let $(X, d)$ be a metric space and $Y, Z$ be nonempty subsets of $X$. Let $J: Y \rightarrow Z$ and $g: Y \rightarrow Y$ be mappings. A point $x \in Y$ such that $d(x, J x)=d(Y, Z)$ is called $a$ best proximity point of J. A point $x \in Y$ is said to be a coincidence best proximity point of the pair $(g, J)$ if $d(g x, J x)=d(Y, Z)$. We give the meaning of the sets $Y_{0}$ and $Z_{0}$ as follows:

$$
\begin{aligned}
& d(Y, Z):=\inf \{d(x, y): x \in Y \text { and } y \in Z\}, \\
& Y_{0}:=\{x \in Y: d(x, y)=d(Y, Z) \text { for some } y \in Z\}, \\
& Z_{0}:=\{y \in Z: d(x, y)=d(Y, Z) \text { for some } x \in Y\} .
\end{aligned}
$$

A mapping $J: Y \cup Z \rightarrow Y \cup Z$ is called a cyclic mapping if $J(Y) \subseteq Z$ and $J(Z) \subseteq Y$.

Definition 2.3 ([11]) A mapping $J: Y \cup Z \rightarrow Y \cup Z$ is called a cyclic contraction if the following conditions hold:

(i) $J$ is a cyclic mapping;

(ii) There exists $k \in(0,1)$ such that $d(J x, J y) \leq k d(x, y)+(1-k) d(Y, Z)$ for all $x \in Y$, $y \in Z$.

Definition 2.4 ([15]) Let $Y, Z$ be two nonempty closed subsets of a complete metric space $(X, d)$, and let $J, T$ be two self-maps on $Y \cup Z$. We call $(J, T)$ a semicyclic contraction pair if the following conditions hold:

(i) $J$ is a cyclic mapping;

(ii) There exists $\alpha \in(0,1)$ such that $d(J x, T y) \leq \alpha d(x, y)+(1-\alpha) d(Y, Z)$ for all $x \in Y$, $y \in Z$.

Obviously, in the case that $J=T$, a semicyclic contraction pair reduces to a cyclic contraction.

Definition 2.5 ([5]) Given non-self-mappings $J: Y \rightarrow Z$ and $T: Z \rightarrow Y$, the pair $(J, T)$ is said to form a proximal cyclic contraction if there exists a nonnegative number $\alpha<1$ such that

$$
\left.\begin{array}{l}
d(u, J x)=d(Y, Z) \\
d(v, T y)=d(Y, Z)
\end{array}\right\} \quad \Longrightarrow \quad d(u, v) \leq \alpha d(x, y)+(1-\alpha) d(Y, Z)
$$

for all $u, x$ in $Y$ and $v, y$ in $Z$. 
Definition 2.6 ([5]) A mapping $J: Y \rightarrow Z$ is said to be a proximal contraction of the first kind if there exists a nonnegative number $\alpha<1$ such that

$$
\left.\begin{array}{l}
d\left(u_{1}, J x_{1}\right)=d(Y, Z) \\
d\left(u_{2}, J x_{2}\right)=d(Y, Z)
\end{array}\right\} \quad \Longrightarrow \quad d\left(u_{1}, u_{2}\right) \leq \alpha d\left(x_{1}, x_{2}\right),
$$

for all $u_{1}, u_{2}, x_{1}, x_{2}$ in $Y$.

Note that, if $J$ is a self-mapping, then, using Definition 2.6, we get that $J$ is a contraction. So, the pair $(J, J)$ forms a proximal cyclic contraction.

Definition 2.7 ([5]) A mapping $J: Y \rightarrow Z$ is said to be a proximal contraction of the second kind if there exists a nonnegative real number $\alpha<1$ such that

$$
\left.\begin{array}{l}
d\left(u_{1}, J x_{1}\right)=d(Y, Z) \\
d\left(u_{2}, J x_{2}\right)=d(Y, Z)
\end{array}\right\} \quad \Rightarrow \quad d\left(J u_{1}, J u_{2}\right) \leq \alpha d\left(J x_{1}, J x_{2}\right),
$$

for all $u_{1}, u_{2}, x_{1}, x_{2}$ in $Y$.

It is remarked that in the case that $J$ is a non-self-mapping, a proximal contraction of the first kind reduces to a contraction and every contraction is a proximal contraction of the second kind.

Definition 2.8 ([5]) Given a mapping $J: Y \rightarrow Z$ and an isometry $g: Y \rightarrow Y$, the mapping $J$ is said to preserve isometric distance with respect to $g$ if

$$
d\left(J g x_{1}, J g x_{2}\right)=d\left(J x_{1}, J x_{2}\right)
$$

for all $x_{1}$ and $x_{2}$ in $Y$.

Also, Basha [5] proved the existence of the following best proximity point in a complete metric space.

Theorem 2.9 (Basha [5], Theorem 3.1) Let $Y$ and $Z$ be nonempty closed subsets of a complete metric space such that $Y_{0}$ and $Z_{0}$ are nonempty. Let $J: Y \rightarrow Z, T: Z \rightarrow Y$, and $g: Y \cup Z \rightarrow Y \cup Z$ satisfy the following conditions:

(a) $J$ and $T$ are proximal contractions of the first kind;

(b) $J\left(Y_{0}\right) \subseteq Z_{0}$ and $T\left(Z_{0}\right) \subseteq Y_{0}$;

(c) The pair $(J, T)$ forms a proximal cyclic contraction;

(d) $g$ is an isometry;

(e) $Y_{0} \subseteq g\left(Y_{0}\right)$ and $Z_{0} \subseteq g\left(Z_{0}\right)$.

Then, there exist a unique element $x$ in $Y$ and a unique element $y$ in $Z$ satisfying

$$
d(g x, J x)=d(Y, Z)=d(g y, T y) \quad \text { and } \quad d(x, y)=d(Y, Z) .
$$

Further, for any fixed element $x_{0}$ in $Y_{0}$, the sequence $\left\{x_{n}\right\}$, defined by

$$
d\left(g x_{n+1}, J x_{n}\right)=d(Y, Z)
$$


converges to the element $x$. For any fixed element $y_{0}$ in $Z_{0}$, the sequence $\left\{y_{n}\right\}$, defined by

$$
d\left(g y_{n+1}, T y_{n}\right)=d(Y, Z)
$$

converges to the element $y$.

Motivated by Eldred and Veeramani [11], Gabeleh and Abker [15], and Basha [5], and the idea of Berinde [7], we introduce the new classes of proximal Berinde $g$-contractions of the first and second kind, and proximal Berinde $g$-cyclic contractions which are more general than the class of non-self-mappings in [5]. Moreover, we obtain a coincidence best proximity point theorem. We also give some examples to illustrate our results.

\section{Main results}

In this section, we shall first introduce proximal Berinde $g$-contractions of the first and second kind, as well as proximal Berinde $g$-cyclic contractions. Then, we prove the existence of coincidence best proximity points for these non-self-mappings in a metric space. Throughout this section, $Y$ and $Z$ are two nonempty subsets of a metric space $(X, d)$.

Definition 3.1 Let $J: Y \rightarrow Z, T: Z \rightarrow Y$ and $g: Y \cup Z \rightarrow Y \cup Z$ be mappings. An element $(x, y) \in Y \times Z$ is called a coincidence best proximity point of the triple $(g, J, T)$ if $(g x, g y) \in$ $Y \times Z$ and $d(g x, J x)=d(Y, Z)=d(g y, T y)$.

Definition 3.2 Let $J: Y \rightarrow Z$ and $g: Y \rightarrow Y$ be mappings. A mapping $J$ is said to be a proximal Berinde g-contraction of the first kind if there exist $\alpha \in[0,1)$ and $L_{1} \geq 0$ such that for all $x_{1}, x_{2}, u_{1}, u_{2} \in Y$,

$$
\left.\begin{array}{rl}
d\left(g u_{1}, J x_{1}\right)=d(Y, Z) \\
d\left(g u_{2}, J x_{2}\right)=d(Y, Z)
\end{array}\right\} \Longrightarrow \begin{aligned}
d\left(g u_{1}, g u_{2}\right) \leq & \alpha d\left(g x_{1}, g x_{2}\right) \\
& +L_{1} \min \left\{d\left(g x_{1}, g u_{2}\right), d\left(g x_{2}, g u_{1}\right)\right\}
\end{aligned}
$$

From Definition 3.2, if we take $L_{1}=0$ and $g$ as the identity mapping, then a proximal Berinde $g$-contraction of the first kind reduces to a proximal contraction of the first kind which was introduced by Basha [5].

Example 3.3 Consider the complete metric space $\mathbb{R}^{2}$ with the usual metric defined by

$$
d(x, y)=\sqrt{\left(x_{1}-y_{1}\right)^{2}+\left(x_{2}-y_{2}\right)^{2}}, \quad \text { for all } x=\left(x_{1}, x_{2}\right), y=\left(y_{1}, y_{2}\right) \in \mathbb{R}^{2} .
$$

Let $Y=\{(1, y): y \in[-1,0]\} \cup\{(0,0)\}$ and $Z=\left\{(x, y) \in \mathbb{R}^{2}: x^{2}+y^{2}=1\right.$ and $\left.x \in[-1,0]\right\}$. Then $d(Y, Z)=1$. Define the mappings $J: Y \rightarrow Z$ and $g: Y \rightarrow Y$ as follows:

$$
J(x, y)= \begin{cases}(0,1), & \text { if }(x, y)=(0,0) \\ \left(\frac{y}{2},-\sqrt{1-\frac{y^{2}}{4}}\right), & \text { if }(x, y) \in Y-\{(0,0)\}\end{cases}
$$

and

$$
g(x, y)= \begin{cases}\left(x, \frac{y}{2}\right), & \text { if }(x, y) \in Y-\{(1,-1)\} \\ (1,-1), & \text { if }(x, y)=(1,-1)\end{cases}
$$


Now, we will show that $J$ is a proximal Berinde $g$-contraction of the first kind. Let $x_{1}=$ $\left(x_{1}^{\prime}, y_{2}^{\prime}\right), x_{2}=\left(x_{2}^{\prime}, y_{2}^{\prime}\right) \in Y$ and $u_{1}, u_{2} \in Y$ be such that

$$
d\left(g u_{1}, J x_{1}\right)=d(Y, Z)=d\left(g u_{2}, J x_{2}\right) .
$$

We shall divide the consideration into five cases.

Case 1. Let $x_{1}=(0,0)=x_{2}$. Then $J x_{1}=(0,1)=J x_{2}$, and so $g u_{1}=g u_{2}=(0,0)$. Obviously, $J$ satisfies the inequality (3.1), for all $L_{1} \geq 0$.

Case 2. Let $x_{1}=(0,0), x_{2}=\left(x_{2}^{\prime}, y_{2}^{\prime}\right) \in Y-\{(0,0)\}$ (similarly, if $\left.x_{2}=(0,0), x_{1} \in Y-\{(0,0)\}\right)$. Then $J x_{1}=(0,1), J x_{2}=\left(\frac{y_{2}^{\prime}}{2},-\sqrt{1-\frac{y_{2}^{\prime 2}}{4}}\right)$, and so $g u_{1}=(0,0), g u_{2} \in\{(0,0),(1,-1)\}$.

If $g u_{2}=(0,0)$, then $J$ satisfies the inequality (3.1), for all $L_{1} \geq 0$.

If $g u_{2}=(1,-1)$, then $x_{2}=(1,0)$. This implies

$$
d\left(g u_{1}, g u_{2}\right)=\sqrt{2}, d\left(g x_{1}, g x_{2}\right)=1 \quad \text { and } \min \left\{d\left(g x_{1}, g u_{2}\right), d\left(g x_{2}, g u_{1}\right)\right\}=1 .
$$

It follows that

$$
d\left(g u_{1}, g u_{2}\right) \leq \frac{1}{2} d\left(g x_{1}, g x_{2}\right)+L_{1} \min \left\{d\left(g x_{1}, g u_{2}\right), d\left(g x_{2}, g u_{1}\right)\right\},
$$

for all $L_{1} \geq \sqrt{2}-\frac{1}{2}$.

Case 3. Let $x_{1}, x_{2} \in Y-\{(0,0),(1,0)\}$. Then $g u_{1}=g u_{2}=(0,0)$. Obviously, $J$ satisfies the inequality (3.1), for all $L_{1} \geq 0$.

Case 4. Let $x_{1}=(1,0)=x_{2}$. Then $J x_{1}=(0,-1)=J x_{2}$, and so $g u_{1}, g u_{2} \in\{(0,0),(1,-1)\}$. Obviously, if $g u_{1}=g u_{2}$, then $J$ satisfies the inequality (3.1) for all $L_{1} \geq 0$.

Suppose that $g u_{1} \neq g u_{2}$. Then

$$
d\left(g u_{1}, g u_{2}\right)=\sqrt{2}, d\left(g x_{1}, g x_{2}\right)=0 \quad \text { and } \quad \min \left\{d\left(g x_{1}, g u_{2}\right), d\left(g x_{2}, g u_{1}\right)\right\}=1 .
$$

It follows that

$$
d\left(g u_{1}, g u_{2}\right) \leq \frac{1}{2} d\left(g x_{1}, g x_{2}\right)+L_{1} \min \left\{d\left(g x_{1}, g u_{2}\right), d\left(g x_{2}, g u_{1}\right)\right\}
$$

where $L_{1} \geq \sqrt{2}$.

Case 5. Let $x_{1}=(1,0)$ and $x_{2} \in\{(0,0),(1,0)\}$ (similarly, if $x_{2}=(1,0), x_{1} \in Y-\{(0,0)$, $(1,0)\})$. Then $J x_{1}=(0,-1), J x_{2}=\left(\frac{y_{2}^{\prime}}{2},-\sqrt{1-\frac{y_{2}^{\prime 2}}{4}}\right)$, and so $g u_{1} \in\{(0,0),(1,-1)\}, g u_{2}=(0,0)$. Obviously, if $g u_{1}=g u_{2}=(0,0)$, then $J$ satisfies the inequality (3.1) for all $L_{1} \geq 0$.

Suppose that $g u_{1} \neq g u_{2}$. Then

$$
d\left(g u_{1}, g u_{2}\right)=\sqrt{2}, d\left(g x_{1}, g x_{2}\right)=\frac{y_{2}^{\prime}}{2} \quad \text { and } \quad \min \left\{d\left(g x_{1}, g u_{2}\right), d\left(g x_{2}, g u_{1}\right)\right\}=1 .
$$

It follows that

$$
d\left(g u_{1}, g u_{2}\right) \leq \frac{1}{2} d\left(g x_{1}, g x_{2}\right)+L_{1} \min \left\{d\left(g x_{1}, g u_{2}\right), d\left(g x_{2}, g u_{1}\right)\right\},
$$

where $L_{1} \geq \sqrt{2}$. From each case, we can conclude that $J$ is a proximal Berinde $g$ contraction of the first kind with $\alpha=\frac{1}{2}$ and $L_{1}=\sqrt{2}$. From Case 4 , we noticed that $J$ is not a proximal contraction of the first kind when $L_{1}=0$ and $g$ is the identity mapping. 
Definition 3.4 Let $J: Y \rightarrow Z$ and $g: Y \rightarrow Y$ be mappings. A mapping $J$ is said to be a proximal Berinde g-contraction of the second kind if there exist $\beta \in[0,1)$ and $L_{2} \geq 0$ such that for all $x_{1}, x_{2}, u_{1}, u_{2} \in Y$,

$$
\left.\begin{array}{l}
d\left(g u_{1}, J x_{1}\right)=d(Y, Z) \\
d\left(g u_{2}, J x_{2}\right)=d(Y, Z)
\end{array}\right\} \Longrightarrow \begin{gathered}
d\left(J g u_{1}, J g u_{2}\right) \leq \beta d\left(J g x_{1}, J g x_{2}\right) \\
+L_{2} \min \left\{d\left(J g x_{1}, J g u_{2}\right)\right. \\
\left.d\left(J g x_{2}, J g u_{1}\right)\right\}
\end{gathered}
$$

From Definition 3.4, if we take $L_{2}=0$ and $g$ as the identity mapping, then a proximal Berinde $g$-contraction of the second kind reduces to a proximal contraction of the second kind which was introduced by Basha [5].

Definition 3.5 Let $J: Y \rightarrow Z, T: Z \rightarrow Y$ and $g: Y \cup Z \rightarrow Y \cup Z$ be mappings. The pair $(J, T)$ is said to be a proximal Berinde $g$-cyclic contraction if there exist $\gamma \in[0,1)$ and $L \geq 0$ such that

$$
\left.\begin{array}{l}
d\left(g u_{1}, J x_{1}\right)=d(Y, Z) \\
d\left(g u_{1}, T x_{2}\right)=d(Y, Z)
\end{array}\right\} \Longrightarrow \begin{aligned}
d\left(g u_{1}, g u_{2}\right) \leq & \gamma d\left(g x_{1}, g x_{2}\right) \\
& +(1-\gamma) d(Y, Z)+L d\left(g x_{1}, g u_{1}\right),
\end{aligned}
$$

for all $x_{1}, g u_{1} \in Y$ and $x_{2}, g u_{2} \in Z$.

From Definition 3.5, if we take $L=0$ and $g$ as the identity mapping, then a proximal Berinde $g$-cyclic contraction reduces to a proximal cyclic contraction which was introduced by Basha [5].

Before giving the coincidence best proximity point theorems, we give the following lemmas, which are important tools for proving the existence of coincidence best proximity points in a metric space.

Lemma 3.6 Let $Y$ and $Z$ be nonempty subsets of a metric space $(X, d)$ such that $Y_{0}$ is nonempty. Let $J: Y \rightarrow Z$ and $g: Y \rightarrow Y$ with $J\left(Y_{0}\right) \subseteq Z_{0}$ and $Y_{0} \subseteq g\left(Y_{0}\right)$. Then

(i) For each $x \in Y_{0}$, there exists $y \in Y_{0}$ such that $d(g y, J x)=d(Y, Z)$;

(ii) For each $x_{0} \in Y_{0}$, the sequence $\left\{x_{n}\right\}$ in $Y_{0}$ satisfies

$$
d\left(g x_{n+1}, J x_{n}\right)=d(Y, Z), \quad \text { for all } n \in \mathbb{N}^{*} .
$$

Proof (i) Let $x \in Y_{0}$ be given. Since $J\left(Y_{0}\right) \subseteq Z_{0}, J x \in Z_{0}$. Then, there exists $z \in Y_{0}$ such that $D(z, J x)=d(Y, Z)$. Since $Y_{0} \subseteq g\left(Y_{0}\right)$, there exists $y \in Y_{0}$ such that $z=g y$, and then $d(g y, J x)=$ $d(Y, Z)$.

(ii) Let $x_{0} \in Y_{0}$ be given. By using (i), we get that there exists $x_{1} \in Y_{0}$ such that

$$
d\left(g x_{1}, J x_{0}\right)=d(Y, Z)
$$

Again, from $x_{1} \in Y_{0}$ and using (i), we have that there exists $x_{2} \in Y_{0}$ such that

$$
d\left(g x_{2}, J x_{1}\right)=d(Y, Z)
$$


Continuing in the same way, we can establish a sequence $\left\{x_{n}\right\}$ in $Y_{0}$ such that

$$
d\left(g x_{n+1}, J x_{n}\right)=d(Y, Z), \quad \text { for all } n \in \mathbb{N}^{*} .
$$

The proof is completed.

Lemma 3.7 Let $Y$ be a nonempty closed subset of a complete metric space $(X, d)$. Suppose that $\left\{x_{n}\right\}$ is a sequence in $Y$ and there exists $\alpha \in[0,1)$ such that

$$
d\left(x_{n}, x_{n+1}\right) \leq \alpha^{n} d\left(x_{0}, x_{1}\right), \quad \text { for all } n \in \mathbb{N},
$$

then a sequence $\left\{x_{n}\right\}$ converges to some point $x$ in $Y$.

Proof We shall divide our proof into two cases.

Case 1. If $d\left(x_{0}, x_{1}\right)=0$ or $\alpha=0$, then we get that $\left\{x_{n}\right\}$ converges to some point $x$ in $Y$.

Case 2. If $d\left(x_{0}, x_{1}\right) \neq 0$ and $\alpha \neq 0$, then for each $m, n \in \mathbb{N}$ such that $m>n$,

$$
\begin{aligned}
d\left(x_{m}, x_{n}\right) & \leq d\left(x_{n}, x_{n+1}\right)+d\left(x_{n+1}, x_{n+2}\right)+\cdots+d\left(x_{m-1}, x_{m}\right) \\
& \leq \alpha^{n} d\left(x_{0}, x_{1}\right)+\alpha^{n+1} d\left(x_{0}, x_{1}\right)+\cdots+\alpha^{m-1} d\left(x_{0}, x_{1}\right) \\
& <\frac{\alpha^{n}}{1-\alpha} d\left(x_{0}, x_{1}\right) .
\end{aligned}
$$

Since $\alpha \in(0,1),\left\{x_{n}\right\}$ is a Cauchy sequence in $X$, and hence converges to some point $x$ in $Y$ since $Y$ is closed.

Lemma 3.8 Let $Y$ and $Z$ be nonempty closed subsets of a complete metric space $(X, d)$, with $Y_{0}$ being nonempty. Let $J: Y \rightarrow Z$ and $g: Y \rightarrow Y$ satisfy the following conditions:

(i) $J$ is a proximal Berinde $g$-contraction of the first kind such that $J\left(Y_{0}\right) \subseteq Z_{0}$;

(ii) $g$ is an isometry with $Y_{0} \subseteq g\left(Y_{0}\right)$.

Then, there exists a point $x \in Y$ such that $x_{n} \rightarrow x$, as $n \rightarrow \infty$.

Proof Let $x_{0} \in Y_{0}$ be given. By Lemma 3.6, we can find a sequence $\left\{x_{n}\right\}$ in $Y_{0}$ defined by

$$
d\left(g x_{n+1}, J x_{n}\right)=d(Y, Z), \quad \text { for all } n \in \mathbb{N}^{*} .
$$

Since $J$ is a proximal Berinde $g$-contraction of the first kind and

$$
d\left(g x_{n}, J x_{n-1}\right)=d(Y, Z)=d\left(g x_{n+1}, J x_{n}\right), \quad \text { for all } n \in \mathbb{N},
$$

we obtain that for each $n \in \mathbb{N}$,

$$
\begin{aligned}
d\left(g x_{n}, g x_{n+1}\right) & \leq \alpha d\left(g x_{n-1}, g x_{n}\right)+L \min \left\{d\left(g x_{n-1}, g x_{n+1}\right), d\left(g x_{n}, g x_{n}\right)\right\} \\
& =\alpha d\left(g x_{n-1}, g x_{n}\right) .
\end{aligned}
$$

By using (3.4), we get

$$
d\left(g x_{n}, g x_{n+1}\right) \leq \alpha^{n} d\left(g x_{0}, g x_{1}\right), \quad \text { for all } n \in \mathbb{N} .
$$


It implies that

$$
d\left(x_{n}, x_{n+1}\right) \leq \alpha^{n} d\left(x_{0}, x_{1}\right), \quad \text { for all } n \in \mathbb{N},
$$

because $g$ is an isometry. Since $\alpha \in[0,1)$ and using Lemma 3.7, we obtain that there exists $x \in Y$ such that $x_{n} \rightarrow x$ as $n \rightarrow \infty$.

Theorem 3.9 Let $Y$ and $Z$ be nonempty closed subsets of a complete metric space $(X, d)$ such that $Y_{0}$ is nonempty. Let $J: Y \rightarrow Z, T: Z \rightarrow Y$, and $g: Y \cup Z \rightarrow Y \cup Z$ satisfy the following conditions:

(i) $J$ and $T$ are proximal Berinde $g$-contractions of the first kind, i.e., there exist $\alpha, \beta \in[0,1)$ and $L_{1}, L_{2} \geq 0$ such that $J$ and $T$ satisfy the condition (3.1), respectively;

(ii) $J\left(Y_{0}\right) \subseteq Z_{0}$ and $T\left(Z_{0}\right) \subseteq Y_{0}$;

(iii) $g$ is an isometry with $Y_{0} \subseteq g\left(Y_{0}\right)$ and $Z_{0} \subseteq g\left(Z_{0}\right)$;

(iv) The pair $(J, T)$ is a proximal Berinde g-cyclic contraction.

Then, there exists a point $x \in Y$ and there exists a point $y \in Z$ such that

$$
d(g x, J x)=d(g y, T y)=d(x, y)=d(Y, Z) .
$$

Moreover, for any fixed $x_{0} \in Y_{0}$, the sequence $\left\{x_{n}\right\}$ defined by

$$
d\left(g x_{n+1}, J x_{n}\right)=d(Y, Z), \quad \text { for all } n \in \mathbb{N}^{*}
$$

converges to the element $x$, and for any fixed $y_{0} \in Z_{0}$, the sequence $\left\{y_{n}\right\}$ defined by

$$
d\left(g y_{n+1}, T y_{n}\right)=d(Y, Z), \quad \text { for all } n \in \mathbb{N}^{*}
$$

converges to the element $y$.

In addition, if $\alpha+L_{1}<1$ and $\beta+L_{2}<1$, then there exists a unique element $x$ and there exists a unique element $y$ which satisfy the equation (3.5).

Proof From $J$ satisfies the conditions (i)-(iii) and using Lemma 3.8, we get that for $x_{0} \in Y_{0}$, we can find a sequence $\left\{x_{n}\right\}$ in $Y_{0}$ such that

$$
d\left(g x_{n+1}, J x_{n}\right)=d(Y, Z), \quad \text { for all } n \in \mathbb{N}^{*},
$$

and which converges to some element $x \in Y$. Similarly, for $y_{0} \in Z_{0}$, we can find a sequence $\left\{y_{n}\right\}$ in $Z_{0}$ such that

$$
d\left(g y_{n+1}, J y_{n}\right)=d(Y, Z), \quad \text { for all } n \in \mathbb{N}^{*},
$$

and which converges to some element $y \in Z$. Since the pair $(J, T)$ is a proximal Berinde $g$-cyclic contraction and

$$
d\left(g x_{n+1}, J x_{n}\right)=d(Y, Z)=d\left(g y_{n+1}, T y_{n}\right), \quad \text { for all } n \in \mathbb{N}^{*},
$$


there exist $\gamma \in[0,1)$ and $L \geq 0$ such that

$$
d\left(g x_{n+1}, g y_{n+1}\right) \leq \gamma d\left(g x_{n}, g y_{n}\right)+(1-\gamma) d(Y, Z)+L d\left(g x_{n}, g x_{n+1}\right) .
$$

It implies that

$$
d\left(x_{n+1}, y_{n+1}\right) \leq \gamma d\left(x_{n}, y_{n}\right)+(1-\gamma) d(Y, Z)+L d\left(x_{n}, x_{n+1}\right) .
$$

Taking limit as $n \rightarrow \infty$, we have $d(x, y) \leq \gamma d(x, y)+(1-\gamma) d(Y, Z)$, and so $d(x, y) \leq d(Y, Z)$. Then $d(x, y)=d(Y, Z)$, that is, $x \in Y_{0}$ and $y \in Z_{0}$. Since $J\left(Y_{0}\right) \subseteq Z_{0}$ and $T\left(Z_{0}\right) \subseteq Y_{0}, J x \in Z_{0}$ and $T y \in Y_{0}$. Hence there exist $w \in Y_{0}$ and $v \in Z_{0}$ such that

$$
d(g w, J x)=d(Y, Z)=d(g v, T y),
$$

since $Y_{0} \subseteq g\left(Y_{0}\right)$ and $Z_{0} \subseteq g\left(Z_{0}\right)$. Since $J$ is a proximal Berinde $g$-contraction of the first kind and

$$
d(g w, J x)=d(Y, Z)=d\left(g x_{n+1}, J x_{n}\right), \quad \text { for all } n \in \mathbb{N}^{*},
$$

we obtain that

$$
\begin{aligned}
d\left(g w, g x_{n+1}\right) & \leq \alpha d\left(g x, g x_{n}\right)+L_{1} \min \left\{d\left(g x, g x_{n+1}\right), d\left(g w, g x_{n}\right)\right\} \\
& \leq \alpha d\left(g x, g x_{n}\right)+L_{1} d\left(g x, g x_{n+1}\right) .
\end{aligned}
$$

Taking $n \rightarrow \infty$ in above inequality, by the continuity of $g$, we get $d(g w, g x)=0$, and so, $g x=g w$. It implies that

$$
d(g x, J x)=d(Y, Z)
$$

Similarly, it is easy to verify that $d(g y, T y)=d(Y, Z)$. Thus, we can conclude that

$$
d(g x, J x)=d(g y, T y)=d(x, y)=d(Y, Z) .
$$

Therefore, $(x, y)$ is a coincidence best proximity point of the triple $(g, J, T)$. Next, we will show that $(x, y)$ is unique. Suppose that $\alpha+L_{1}<1, \beta+L_{2}<1$ and there exists $g w \in Y_{0}$ such that

$$
d(g w, J w)=d(Y, Z)
$$

Since $J$ is a proximal Berinde $g$-contraction of the first kind, we have that

$$
\begin{aligned}
d(g x, g w) & \leq \alpha d(g x, g w)+L_{1} \min \{d(g x, g w), d(g w, g x)\} \\
& \leq\left(\alpha+L_{1}\right) d(g x, g w) .
\end{aligned}
$$

Since $\alpha+L_{1}<1, d(g x, g w)=0$. It follows that $g x=g w$, which implies that there exists a unique $x \in Y$ such that $d(g x, J x)=d(Y, Z)$. Similarly, we can show that there exists a unique 
$y \in Z$ such that $d(g y, T y)=d(Y, Z)$. Therefore, the pair $(x, y)$ is a unique coincidence best proximity point of the triple $(g, J, T)$.

Example 3.10 Consider the complete metric space $\mathbb{R}^{2}$ with the usual metric defined by

$$
d(x, y)=\sqrt{\left(x_{1}-y_{1}\right)^{2}+\left(x_{2}-y_{2}\right)^{2}}, \quad \text { for all } x=\left(x_{1}, x_{2}\right), y=\left(y_{1}, y_{2}\right) \in \mathbb{R}^{2} .
$$

Let $Y=\left\{(x, 0) \in \mathbb{R}^{2}: x \in[0,1]\right\}$ and $Z=\left\{(y, 1) \in \mathbb{R}^{2}: y \in[0,1]\right\}$. Then $d(Y, Z)=1, Y_{0}=Y$ and $Z_{0}=Z$. Define the mappings $J: Y \rightarrow Z, T: Z \rightarrow Y$, and $g: Y \cup Z \rightarrow Y \cup Z$ by

$$
J(x, 0)=\left(\frac{x}{2}, 1\right), \quad J(y, 1)=\left(\frac{y}{2}, 0\right) \quad \text { and } \quad g(x, y)=(-x, y) .
$$

Obviously, $g$ is an isometry, $J$ and $T$ are proximal Berinde $g$-contractions of the first kind, and the pair $(J, T)$ is a proximal Berinde $g$-cyclic contraction. Clearly, the mappings $J$, $T$, and $g$ satisfy the conditions (ii) and (iv). Therefore, all hypothesis of Theorem 3.9 are satisfied. Moreover, $(0,0) \in Y$ is a coincidence best proximity point of the pair $(g, J)$ and $(0,1) \in Z$ is a coincidence best proximity point of the pair $(g, T)$, i.e., $((0,0),(0,1))$ is a coincidence best proximity point of the triple $(g, J, T)$.

If we take $L_{1}=0, L_{2}=0$ and $L=0$ in Theorem 3.9, we obtain the following coincidence best proximity point theorem which is more general than that of Basha [5].

Corollary 3.11 Let $Y$ and $Z$ be nonempty closed subsets of a complete metric space $(X, d)$ such that $Y_{0}$ is nonempty. Let $J: Y \rightarrow Z, T: Z \rightarrow Y$, and $g: Y \cup Z \rightarrow Y \cup Z$ satisfy the following conditions:

(i) $J$ and $T$ are proximal $g$-contractions of the first kind;

(ii) $J\left(Y_{0}\right) \subseteq Z_{0}$ and $J\left(Z_{0}\right) \subseteq Y_{0}$;

(iii) $g$ is an isometry with $Y_{0} \subseteq g\left(Y_{0}\right)$ and $Z_{0} \subseteq g\left(Z_{0}\right)$;

(iv) The pair $(J, T)$ is a proximal $g$-cyclic contraction.

Then, there exists a unique point $x \in Y$ and there exists a unique point $y \in Z$ such that

$$
d(g x, J x)=d(g y, T y)=d(x, y)=d(Y, Z) .
$$

Moreover, for any fixed $x_{0} \in Y_{0}$, the sequence $\left\{x_{n}\right\}$ defined by

$$
d\left(g x_{n+1}, J x_{n}\right)=d(Y, Z), \quad \text { for all } n \in \mathbb{N}^{*}
$$

converges to the element $x$ and for any fixed $y_{0} \in Z_{0}$, the sequence $\left\{y_{n}\right\}$ defined by

$$
d\left(g y_{n+1}, T y_{n}\right)=d(Y, Z), \quad \text { for all } n \in \mathbb{N}^{*}
$$

converges to the element $y$.

If $g$ is the identity mapping, we immediately obtain the following corollary as follows.

Corollary 3.12 Let $Y$ and $Z$ be nonempty closed subsets of a complete metric space $(X, d)$ such that $Y_{0}$ is nonempty. Let $J: Y \rightarrow Z$ and $T: Z \rightarrow Y$ satisfy the following conditions: 
(i) $J$ and $T$ are proximal contractions of the first kind;

(ii) $J\left(Y_{0}\right) \subseteq Z_{0}$ and $J\left(Z_{0}\right) \subseteq Y_{0}$;

(iii) The pair $(J, T)$ is a proximal cyclic contraction.

Then, there exist a unique point $x \in Y$ and a unique point $y \in Z$ such that

$$
d(x, J x)=d(y, T y)=d(x, y)=d(Y, Z) .
$$

Moreover, for any fixed $x_{0} \in Y_{0}$, the sequence $\left\{x_{n}\right\}$ defined by

$$
d\left(x_{n+1}, J x_{n}\right)=d(Y, Z), \quad \text { for all } n \in \mathbb{N}^{*}
$$

converges to the element $x$ and, for any fixed $y_{0} \in Z_{0}$, the sequence $\left\{y_{n}\right\}$ defined by

$$
d\left(y_{n+1}, T y_{n}\right)=d(Y, Z), \quad \text { for all } n \in \mathbb{N}^{*}
$$

converges to the element $y$.

Theorem 3.13 Let $Y$ and $Z$ be nonempty closed subsets of a complete metric space $(X, d)$ such that $Y_{0}$ is nonempty. Let $J: Y \rightarrow Z$ and $g: Y \rightarrow Y$ satisfy the following conditions:

(i) $J$ is a proximal Berinde g-contraction of the first and second kind, i.e., there exist $\alpha, \beta \in[0,1)$ and $L_{1}, L_{2} \geq 0$ such that $J$ satisfies the conditions (3.1) and (3.2), respectively;

(ii) $J$ preserves the isometric distance with respect to $g$ and $J\left(Y_{0}\right) \subseteq Z_{0}$;

(iii) $g$ is an isometry with $Y_{0} \subseteq g\left(Y_{0}\right)$.

Then, there exists a point $x \in Y$ such that

$$
d(g x, J x)=d(Y, Z)
$$

Moreover, for any fixed $x_{0} \in Y_{0}$, the sequence $\left\{x_{n}\right\}$ defined by

$$
d\left(g x_{n+1}, J x_{n}\right)=d(Y, Z), \quad \text { for all } n \in \mathbb{N}^{*}
$$

converges to the element $x$.

In addition, if $\alpha+L_{1}<1$ and $\beta+L_{2}<1$, then there exists a unique coincidence best proximity point of the pair $(g, J)$.

Proof By Lemma 3.8, it is possible to establish a sequence $\left\{x_{n}\right\}$ in $Y_{0}$ such that

$$
d\left(g x_{n+1}, J x_{n}\right)=d(Y, Z), \quad \text { for all } n \in \mathbb{N}^{*} .
$$

Since $J$ is a proximal Berinde $g$-contraction of the first kind and

$$
d\left(g x_{n}, J x_{n-1}\right)=d(Y, Z)=d\left(g x_{n+1}, J x_{n}\right), \quad \text { for all } n \in \mathbb{N},
$$

there exist $\alpha \in[0,1)$ and $L_{1} \geq 0$ such that

$$
d\left(g x_{n}, g x_{n+1}\right) \leq \alpha d\left(g x_{n-1}, g x_{n}\right)+L_{1} \min \left\{d\left(g x_{n}, g x_{n}\right), d\left(g x_{n-1}, g x_{n+1}\right)\right\}
$$




$$
=\alpha d\left(g x_{n-1}, g x_{n}\right) .
$$

Since $g$ is an isometry, $d\left(x_{n}, x_{n+1}\right) \leq \alpha d\left(x_{n-1}, x_{n}\right)$, for all $n \in \mathbb{N}$.

Hence

$$
d\left(x_{n}, x_{n+1}\right) \leq \alpha^{n} d\left(x_{0}, x_{1}\right), \quad \text { for all } n \in \mathbb{N} .
$$

By Lemma 3.7, we get that there exists $x \in Y_{0}$ such that

$$
x_{n} \rightarrow x \quad \text { as } n \rightarrow \infty .
$$

Since $J$ is a proximity Berinde $g$-contractions of the second kind and due to (3.7), there exist $\beta \in[0,1)$ and $L_{2} \geq 0$ such that

$$
\begin{aligned}
d\left(J g x_{n+1}, J g x_{n}\right) \leq & \beta d\left(J g x_{n}, J g x_{n-1}\right) \\
& +L_{2} \min \left\{d\left(J g x_{n}, J g x_{n}\right), d\left(J g x_{n-1}, J g x_{n+1}\right)\right\} \\
= & \beta d\left(J g x_{n}, J g x_{n-1}\right) .
\end{aligned}
$$

Since $J$ preserves isometric distance with respect to $g$,

$$
d\left(J x_{n+1}, J x_{n}\right) \leq \beta d\left(J x_{n}, J x_{n-1}\right), \quad \text { for all } n \in \mathbb{N} .
$$

This implies that

$$
d\left(J x_{n+1}, J x_{n}\right) \leq \beta^{n} d\left(J x_{0}, J x_{1}\right), \quad \text { for all } n \in \mathbb{N} .
$$

By Lemma 3.7, we get that there exists $y \in Z$ such that

$$
J x_{n} \rightarrow y \quad \text { as } n \rightarrow \infty \text {. }
$$

From (3.8), (3.9), and $d\left(g x_{n+1}, J x_{n}\right)=d(Y, Z)$, we get

$$
d(g x, y)=d(Y, Z)
$$

This implies that $g x \in Y_{0}$. Since $Y_{0} \subseteq g\left(Y_{0}\right)$, there exists $z \in Y_{0}$ such that $g x=g z$. So, $x=z \in$ $Y_{0}$ because $g$ is an isometry. Since $J\left(Y_{0}\right) \subseteq Z_{0}, J x \in Z_{0}$ and there exists $u \in Y_{0}$ such that

$$
d(g u, J x)=d(Y, Z) .
$$

Again, since $J$ is a proximity Berinde $g$-contractions of the first kind and due to (3.7),

$$
\begin{aligned}
d\left(g u, g x_{n+1}\right) & \leq \alpha d\left(g x, g x_{n}\right)+L_{1} \min \left\{d\left(g x, g x_{n+1}\right), d\left(g x_{n}, g u\right)\right\} \\
& \leq \alpha d\left(g x, g x_{n}\right)+L_{1} d\left(g x, g x_{n+1}\right) .
\end{aligned}
$$


Taking limit as $n \rightarrow \infty$, we have $d(g u, g x)=0$. Thus, $g u=g x$. From (3.10), we obtain that

$$
d(g x, J x)=d(Y, Z)
$$

i.e., $x$ is a coincidence best proximity point of the pair $(g, J)$. The uniqueness and remaining path of the proof follows by that of Theorem 3.9.

Example 3.14 Consider the complete metric space $\mathbb{R}$ with the usual metric. Let $Y=[-1,1]$ and $Z=[-4,-3] \cup[3,4]$. Then $d(Y, Z)=2, Y_{0}=\{-1,1\}$ and $Z_{0}=\{-3,3\}$. Define the mappings $J: Y \rightarrow Z$ and $g: Y \rightarrow Y$ by

$$
J x=\left\{\begin{array}{ll}
3, & \text { if } x \text { is rational, } \\
-4, & \text { otherwise, }
\end{array} \text { and } g(x)=-x\right.
$$

Obviously, $g$ is an isometry with $Y_{0} \subseteq g\left(Y_{0}\right)$, $J$ preserves the isometric distance with respect to $g$ and it is a proximal Berinde $g$-contraction of the first and the second kind with $J\left(Y_{0}\right) \subseteq$ $Z_{0}$. Therefore, all hypothesis of Theorem 3.13 are valid. Moreover, $-1 \in Y$ is a coincidence best proximity point of the pair $(g, J)$.

If we suppose that $Y_{0}$ is closed in Theorem 3.13, then we do not need to assume that $J$ is a proximal Berinde $g$-contractions of the second kind. This gives the following theorem.

Theorem 3.15 Suppose that all the assumptions of Lemma 3.8 hold. In addition, suppose that $Y_{0}$ is closed. Then, there exists an element $x$ in $Y$ such that $d(g x, J x)=d(Y, Z)$, i.e., $x$ is a coincidence best proximity point of the pair $(g, J)$.

Proof By the proof of Lemma 3.8, we get that the sequence $\left\{x_{n}\right\}$ in $Y_{0}$ defined by

$$
d\left(g x_{n+1}, J x_{n}\right)=d(Y, Z), \quad \text { for all } n \in \mathbb{N}^{*}
$$

converges to an element $x \in Y$. Since $Y_{0}$ is closed, we obtain that $x \in Y_{0}$. Since $J\left(Y_{0}\right) \subseteq Z_{0}$, there exists $z \in Y_{0}$ such that

$$
d(g z, J x)=d(Y, Z)
$$

Since $J$ is a proximal Berinde $g$-contraction of the first kind and using (3.11), we have

$$
\begin{aligned}
d\left(g x_{n+1}, g z\right) & \leq \alpha d\left(g x_{n}, g x\right)+L \min \left\{d\left(g x_{n}, g z\right), d\left(g x_{n+1}, g x\right)\right\} \\
& \leq \alpha d\left(g x_{n}, g x\right)+L d\left(g x_{n+1}, g x\right) .
\end{aligned}
$$

Taking $n \rightarrow \infty$ in the above inequality, by the continuity of $g$, we get $d(g x, g z)=0$, and so, $g x=g z$. It implies that

$$
d(g x, J x)=d(Y, Z)
$$

i.e., $x$ is a coincidence best proximity point of the pair $(g, J)$. 
If we take $L_{1}=0$ and $L_{2}=0$ in Theorem 3.13, we obtain the following coincidence best proximity point result, which is more general than a coincidence best proximity point result in [5].

Corollary 3.16 Let $Y$ and $Z$ be nonempty closed subsets of a complete metric space $(X, d)$ such that $Y_{0}$ is nonempty. Let $J: Y \rightarrow Z$ and $g: Y \rightarrow Y$ satisfy the following conditions:

(i) $J$ is a proximal contraction of the first and second kind;

(ii) $J$ preserves the isometric distance with respect to $g$ and $J\left(Y_{0}\right) \subseteq Z_{0}$;

(iii) $g$ is an isometry with $Y_{0} \subseteq g\left(Y_{0}\right)$.

Then, there exists a unique element $x \in Y$ such that

$$
d(g x, J x)=d(Y, Z)
$$

Moreover, for any fixed $x_{0} \in Y_{0}$, the sequence $\left\{x_{n}\right\}$ defined by

$$
d\left(g x_{n+1}, J x_{n}\right)=d(Y, Z), \quad \text { for all } n \in \mathbb{N}^{*}
$$

converges to the element $x$.

If $g$ is the identity mapping, we obtain the following result by applying Theorem 3.13 as follows.

Corollary 3.17 Let $Y$ and $Z$ be nonempty closed subsets of a complete metric space $(X, d)$ such that $Y_{0}$ is nonempty. Suppose that $J: Y \rightarrow Z$ is a proximal contraction of the first and the second kind with $J\left(Y_{0}\right) \subseteq Z_{0}$. Then there exists a unique element $x \in Y$ such that

$$
d(x, J x)=d(Y, Z) .
$$

Moreover, for any fixed $x_{0} \in Y_{0}$, the sequence $\left\{x_{n}\right\}$ defined by

$$
d\left(x_{n+1}, J x_{n}\right)=d(Y, Z), \quad \text { for all } n \in \mathbb{N}^{*}
$$

converges to the element $x$.

\section{Acknowledgements}

The authors would like to thank all the benefactors for their remarkable comments, suggestions, and ideas that helped improve this paper. This research was financially supported by the Faculty of Science, Mahasarakham University.

\section{Funding}

This research was financially supported by the Faculty of Science, Mahasarakham University.

\section{Availability of data and materials}

Not applicable.

\section{Competing interests}

The authors declare that they have no competing interests.

Authors' contributions

All authors contributed equally to the writing of this paper. All authors read and approved the final manuscript.

\section{Publisher's Note}

Springer Nature remains neutral with regard to jurisdictional claims in published maps and institutional affiliations. 


\section{References}

1. Abkar, A., Gabeleh, M.: Best proximity points of non-self mappings. Top 21(2), 287-295 (2013)

2. Anuradha, J., Veeramani, P.: Proximal pointwise contraction. Topol. Appl. 156(18), 2942-2948 (2009). https://doi.org/10.1016/j.topol.2009.01.017

3. Ayari, M.I., Mustafa, Z., Jaradat, M.M.: Generalization of best proximity points theorem for non-self proximal contractions of first kind. Fixed Point Theory Appl. 2019, 7 (2019)

4. Banach, S.: Sur les opérations dans les ensembles abstraits et leur application aux équations intégrales. Fundam. Math. 3, 133-181 (1922)

5. Basha, S.S.: Best proximity point theorems generalizing the contraction principle. Nonlinear Anal. 74, 5844-5850 (2011)

6. Basha, S.S., Veeramani, P.: Best proximity pair theorems for multifunctions with open fibres. J. Approx. Theory 103(1), 119-129 (2000)

7. Berinde, V:: Approximating fixed points of weak contractions using the Picard iteration. Nonlinear Anal. Forum 9(1), 43-53 (2004)

8. Berinde, V., Pacurar, M.: Fixed points and continuity of almost contractions. Fixed Point Theory 9(1), 23-34 (2008)

9. Derafshpour, M., Rezapour, S., Shahzad, N.: Best proximity points of cyclic-contractions in ordered metric spaces. Topol. Methods Nonlinear Anal. 37, 193-202 (2011)

10. Du, W.-S., Lakzian, H.: Nonlinear conditions for the existence of best proximity points. J. Inequal. Appl. (2012). https://doi.org/10.1186/1029-242X-2012-206

11. Eldred, A.A., Veeramani, P.: Existence and convergence of best proximity points. J. Math. Anal. Appl. 323(2), 1001-1006 (2006)

12. Fan, K.: Extensions of two fixed point theorems of F.E. Browder. Math. Z. 122, 234-240 (1969)

13. Felicit, J.M., Eldred, A.A.: Best proximity points for cyclical contractive mappings. Appl. Gen. Topol. 16, 119-126 (2015)

14. Gabeleh, M.: Global optimal solutions of non-self mappings. UPB Sci. Bull., Ser. A 75(3), 67-74 (2013)

15. Gabeleh, M., Abkar, A.: Best proximity points for semi-cyclic contractive pairs in Banach spaces. Int. Math. Forum 6 2179-2186 (2011)

16. Hussain, N., Parvaneh, V., Roshan, J.R., Kadelburg, Z: Fixed points of cyclic weakly $(\psi, \varphi, L, A, B)$-contractive mappings in ordered $b$-metric spaces with applications. Fixed Point Theory Appl. 2013, 256 (2013). https://doi.org/10.1186/1687-1812-2013-256

17. Karapinar, E.: Best proximity points of cyclic mappings. Appl. Math. Lett. 25, 1761-1766 (2012)

18. Kirk, W.A., Reich, S., Veeramani, P.: Proximinal retracts and best proximity pair theorems. Numer. Funct. Anal. Optim. 24(7-8), 851-862 (2003)

19. Kirk, W.A., Srinivasan, P.S., Veeramani, P.: Fixed points for mapping cyclic contractions. Fixed Point Theory 4, 79-89 (2003)

20. Latif, A., Roshan, J.R., Parvaneh, V., Hussain, N.: Fixed point results via $\alpha$-admissible mappings and cyclic contractive mappings in partial $b$-metric spaces. J. Inequal. Appl. 2014, 345 (2014). https://doi.org/10.1186/1029-242X-2014-345

21. Mongkolkeha, C., Cho, Y.J., Kumam, P.: Best proximity points for generalized proximal C-contraction mappings in metric spaces with partial orders. J. Inequal. Appl. 2013, 94 (2013)

22. Parvaneh, V., Haddadi, M.R., Aydi, H.: On best proximity point results for some type of mappings. J. Funct. Spaces 2020, Article ID 6298138 (2020)

23. Raj, V.S.: A best proximity point theorem for weakly contractive non-self mappings. Nonlinear Anal., Theory Methods Appl. 74(14), 4804-4808 (2011)

24. Reich, S.: Approximate selections, best approximations, fixed points, and invariant sets. J. Math. Anal. Appl. 62(1), 104-113 (1978)

25. Sehgal, V.M., Singh, S.P.: A theorem on best approximations. Numer. Funct. Anal. Optim. 10(1-2), 181-184 (1989)

26. Vetrivel, V., Veeramani, P., Bhattacharyya, P.: Some extensions of Fan's best approximation theorem. Numer. Funct. Anal. Optim. 13(3-4), 397-402 (1992)

\section{Submit your manuscript to a SpringerOpen ${ }^{\circ}$ journal and benefit from:}

- Convenient online submission

- Rigorous peer review

- Open access: articles freely available online

- High visibility within the field

- Retaining the copyright to your article

Submit your next manuscript at $\gg$ springeropen.com 